\title{
Decolourization of Polyaluminium Chloride and Fungal Sequencing Batch Aerobic Reactor Treated Molasses Spentwash by Ozone
}

\author{
Sanjay S. Singh ${ }^{1}$, Anil Kumar Dikshit ${ }^{2,3,4, *}$ \\ ${ }^{1}$ Department of Civil Engineering, Government Engineering College, Rajkot, 360005, India \\ ${ }^{2}$ Centre for Environmental Science and Engineering, IIT Bombay, Mumbai, 400076, India \\ ${ }^{3}$ School of Civil Engineering, Survey and Construction, University of KwaZulu-Natal, Durban, 4041, South Africa \\ ${ }^{4}$ School of Civil and Environmental Engineering, Nanyang Technological University, 639798, Singapore
}

\begin{abstract}
Molasses spentwash from distilleries is characterized by high COD and color. The treatment of distillery spentwash by coagulation with polyaluminium chloride(PAC) followed by biological treatment with fungal sequencing batch aerobic reactor(FSBAR) resulted in $87 \%$ decolorization. To achieve further decolorization, ozonation of treated distillery spentwash was carried out at different ozone doses and contact times. It was found that $\mathrm{pH}$ had a negligible effect on decolourization. The optimum ozone dose was found to be $4.75 \mathrm{~g} / \mathrm{L}$ at application rate of $3.8 \mathrm{~g} / \mathrm{h}$ for $30 \mathrm{~min}$ with corresponding decolorization being $66 \%$. The overall decolorization obtained by the combined treatment(PAC treatment, FSBAR and Ozonation) was $96 \%$ and the total COD removal was $81 \%$.
\end{abstract}

Keywords COD Removal, Decolorization, Molasses Spentwash, Ozonation

\section{Introduction}

Distilleries generate large amount of spentwash that is of serious environmental concern. The spentwash is characterized by high chemical oxygen demand(COD), high biochemical oxygen demand(BOD), low $\mathrm{pH}$, strong odour and dark brown colour[1,2]. Colour of spentwash is mainly due to melanoidins. The melanoidins are difficult to remove by conventional biological treatment such as anaerobic digestion and the activated sludge process[3]. However, fungal species have been reported for having potential to decolourize molasses spentwash[4]. Physical treatment like coagulation with Polyaluminium chloride(PAC) is also very effective in decolourization of DSW[5]. In the earlier studies by the authors, digested spentwash(DSW) was pretreated with polyaluminium chloride and fungal decolourization in a fungal sequencing batch aerobic reactor(FSBAR) was performed[6,7]. The total decolourization obtained after fungal treatment of PAC treated DSW was $87 \%$.

Ozonation is used for decolourization of distillery spentwash in many studies. Oxidation by ozone could achieve $80 \%$ decolorization for biologically treated molasses wastewater with simultaneous $15-25 \%$ COD reduction. It also resulted in improved biodegradability of the effluent.

* Corresponding author:

dikshit@iitb.ac.in (Anil Kumar Dikshit)

Published online at http://journal.sapub.org/ajee

Copyright (C) 2012 Scientific \& Academic Publishing. All Rights Reserved
However, ozone only transforms the chromophore groups but does not degrade the dark coloured poly meric compounds in the effluent $[8,9]$. Ozone in combination with UV radiation enhanced spentwash degradation in terms of COD; however, ozone with hydrogen peroxide showed only marginal reduction even on a very dilute effluent[10]. Sangave et al.(2007) studied ozone and ultrasound as a pre-treatment step for the thermally pretreated spenwash for aerobic treatment by increasing the COD removal efficiency. Ozone was more efficient in COD removal with a 25 -times increase in the rate of biodegradation of ozonated sample along with discoloration of the effluent sample[11].

In this paper, ozonation studies were carried out in order to investigate the effect of ozone on the COD and decolorization of PAC-FSBAR treated distillery spentwash.

\section{Materials and Methods}

\subsection{Wastewater}

Anaerobically digested spentwash(DSW) was obtained from a cane molasses based distillery situated near Mumbai, India. DSW was pretreated chemically with polyaluminium chloride(SVS chemical corporation, Pune, India) and then biologically in FSBAR.

$\mathrm{pH}, \mathrm{COD}$ and color(absolute absorbance at $475 \mathrm{~nm}$ ) of pretreated DSW used for ozone treatment were 3.42, 6400 $\mathrm{mg} / \mathrm{L}$ and 1.43 , respectively.

\subsection{Experimental Setup}


The ozonation studies were conducted in a $28 \mathrm{~cm}$ long bubble column reactor of $6 \mathrm{~cm}$ diameter by varying the contact time at different ozone rates at room temperature. Ozone gas was generated using Ozone Generator(Model OZO 2 VTTL, Ozomax Inc., Quebec, Canada). The generator produced ozone by the corona discharge method using the oxygen as feed gas from an oxygen concentrator(Model 7F-5, Jiangsu Yuyue Medical Equipment Inc., China). The schematic of the experimental setup is shown in Figure 1. A rotameter with a regulating valve for flow adjustment was provided on oxygen concentrator and an output control scale was mounted in front of the generator assembly. Ozone generation was determined by measuring the gas flow rate after calibration. Ozone was supplied at the bottom of the reactor through a gas diffuser. Two ozone traps containing $2 \%$ potassium iodide solution were connected in series with the reactor in order to collect unreacted ozone.

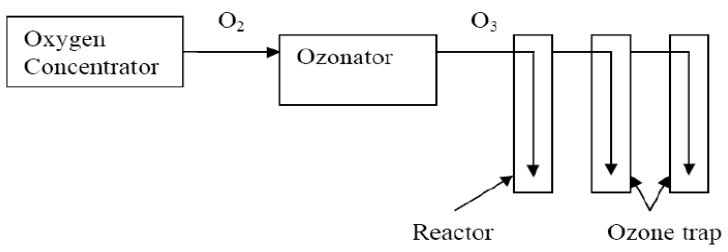

Figure 1. Schematic of the experimental setup

\subsection{Ozonation Studies}

The ozonation studies were conducted by varying the contact time at different ozone rate. All the studies were conducted in the laboratory at room temperature. $400 \mathrm{~mL}$ sample of the FSBAR effluent was filled in the reactor, which was connected serially with two ozone traps containing each $250 \mathrm{~mL}$ of $2 \%$ solution of aqueous potassium iodide. Ozone was bubbled through the aeration port of the reactor with the help of air diffuser. The ozone gas was allowed to react with the sample for a specific time interval and $5 \mathrm{~mL}$ sample were withdrawn at every 5 minutes. The samples were analyzed for COD and colour. The potassium iodide solutions from the ozone traps were titrated with sodium thiosulphate to determine the amount of unreacted ozone in the outlet stream. Knowing the amount of ozone concentration in the feed gas stream, the amount of ozone consumed in the reactor was calculated.

To determine the influence of the $\mathrm{pH}, \mathrm{pH}$ was adjusted to the desired value $(4,6,8,10)$ by addition of sodium hydroxide to the wastewater and the applied ozone dose was kept constant at $6.3 \mathrm{~g} / \mathrm{h}$. Colour and COD were measured at every 5 minutes.

The ozonation reaction was done at $3.8,5$ and $6.3 \mathrm{~g} / \mathrm{h}$ to know the effect of ozone dose on decolourization and COD removal.

For colour measurement, $5 \mathrm{~mL}$ samples were centrifuged at $8,000 \mathrm{rpm}$ for 10 minutes. The supernatant after centrifugation was diluted 10 times for colour reduction measurement. The absorbance was measured at $475 \mathrm{~nm}$ using
Thermo Spectronic visible spectrophotometer. The decolourization yield was expressed as the percentage decrease in absorbance at $475 \mathrm{~nm}$ related to the initial absorbance at the same wavelength.

Chemical oxygen demand(COD) was determined based on the Standard Methods for Examination of Water and Wastewater[12].

\section{Results and Discussion}

Studies were carried out in order to investigate the effect of ozone on the decolourization and COD reduction of FSBAR treated distillery spentwash and results obtained are discussed in following sections.

\subsection{Influence of $\mathbf{p H}$}

Influence of $\mathrm{pH}$ was studied for maximum decolourization of FSBAR treated effluent. At low $\mathrm{pH}$, ozone exclusively react with compounds with specific functional groups through selective direct reactions such as electrophilic, nucleophilic or dipolar addition reactions[13]. Under basic $\mathrm{pH}$, the hydroxide ions catalyze the decomposition of ozone to yield highly reactive and non-selective hydroxyl radicals, which have an oxidation potential higher than that of ozone[14].

The original $\mathrm{pH}$ of treated effluent was about 3.42. The $\mathrm{pH}$ was varied between 4 and 10 in different experiments to study the influence of initial $\mathrm{pH}$. Figure 2 shows the variation of decolourization with time at different $\mathrm{pH}$. The decolourization after 30 min of ozonation at all $\mathrm{pH}$ was $68-70 \%$. This shows that the decolourization of FSBAR treated DSW was independent of $\mathrm{pH}$. Figure 3 shows COD reduction at different $\mathrm{pH}$. The COD reduction at $\mathrm{pH} 10$ was faster than those at other $\mathrm{pH}$. The final COD reduction at all the $\mathrm{pH}$ was $37.5 \%$. The low difference in decolourization and $\mathrm{COD}$ reduction at various $\mathrm{pH}$ indicates that direct reactions of ozone with wastewater organics predominated to radical reactions.

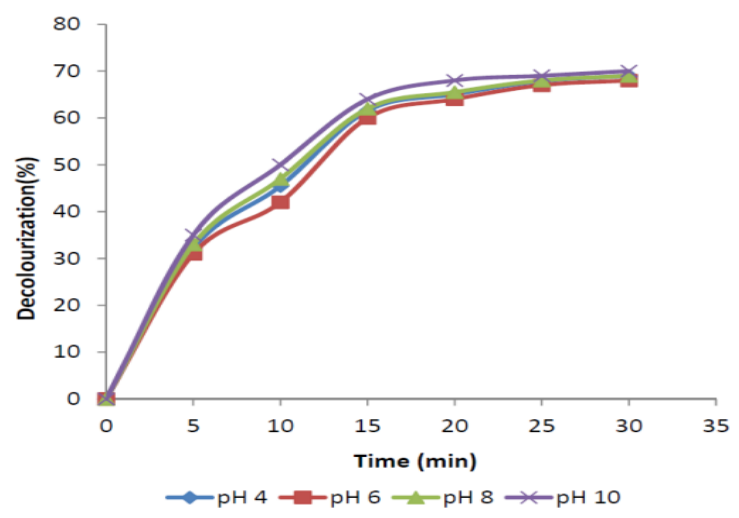

Figure 2. Decolourization of FSBAR treated effluent at various $\mathrm{pH}$.

Coca et al.(2005) also studied the influence of $\mathrm{pH}$ during ozonation of spentwash[14]. The decolourization and COD reduction efficiencies at different $\mathrm{pH}$ were found similar.

As decolourization was not influenced by $\mathrm{pH}$, all subse- 
quent studies were done without any $\mathrm{pH}$ correction.

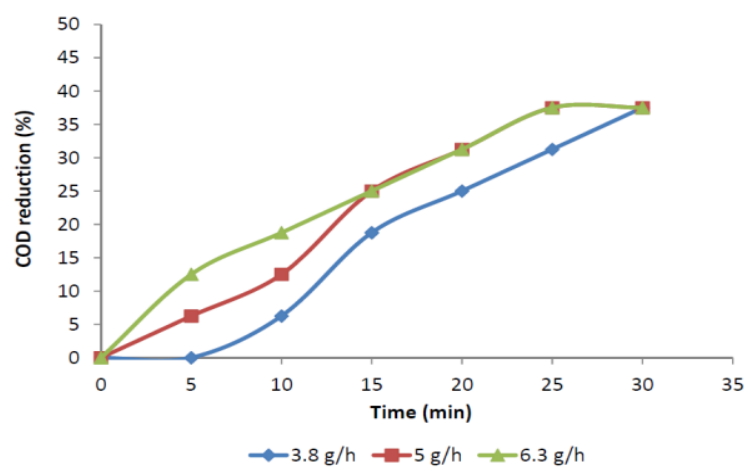

Figure 3. COD reduction of FSBAR treated effluent at various $\mathrm{pH}$.

\subsection{Effect of Ozone Dose}

Ozone application rate was varied from 3.8 to $6.3 \mathrm{~g} / \mathrm{h}$ to assess the effect of the applied ozone dosage on decolourization and COD removal.

\subsubsection{Decolourization}

Figure 4 shows the evolution of decolourization with the reaction time for experiments carried out at different ozone dosages. As a result of ozonation, absorbance at $475 \mathrm{~nm}$ decreased significantly. It reduced from the initial value of 1.43 to 0.48 at $3.8 \mathrm{~g} / \mathrm{h}$ ozone dose and reduced to 0.45 in the case of $5 \mathrm{~g} / \mathrm{h}$ and $6.3 \mathrm{~g} / \mathrm{h}$ ozone doses. The maximum decolourization obtained was $69 \% .4 .75 \mathrm{~g} / \mathrm{L}$ was found out to be optimum dose at applied ozone rate of $3.8 \mathrm{~g} / \mathrm{h}$ for $30 \mathrm{~min}$. Wastewater decolourization occurred mainly at the initial stage of the reaction(i.e. within $20 \mathrm{~min}$ of reaction). Melanoidins have conjugated carbon-carbon double bonds in their structure that are responsible for the brown colour[15]. The colour removal was probably due to the fact that ozone was able to cleavage these conjugated carbon-carbon double bonds.

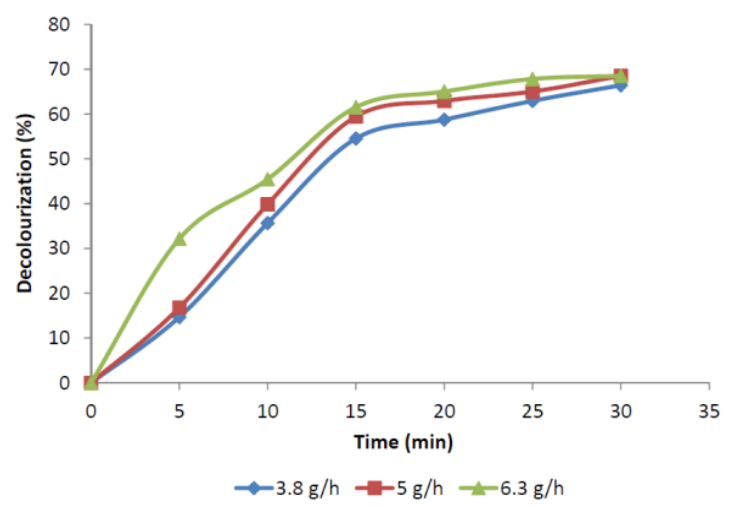

Figure 4. Decolourization of FSBAR treated effluent at various ozone doses.

Pena et al.(2003) studied the ozonation of biologically pretreated molasses spentwash by varying the dose from 1.6 $\mathrm{g} / \mathrm{h}$ to $11.5 \mathrm{~g} / \mathrm{h}$. The decolourization achieved at various doses varied from $71 \%$ to $93 \%[16]$.

\subsubsection{COD Removal}

Figure 5 shows COD removal with the reaction time for experiments carried out at different ozone dosages. Maximum COD reduction of $37.5 \%$ was obtained at all the ozone dosage after $30 \mathrm{~min}$ of reaction. The efficiencies achieved were much lower than those reached in decolourization. The less COD removal may be due to the colour compounds present in wastewater. These compounds react with ozone, leading to organic compounds which might still demand oxygen until their final degradation.

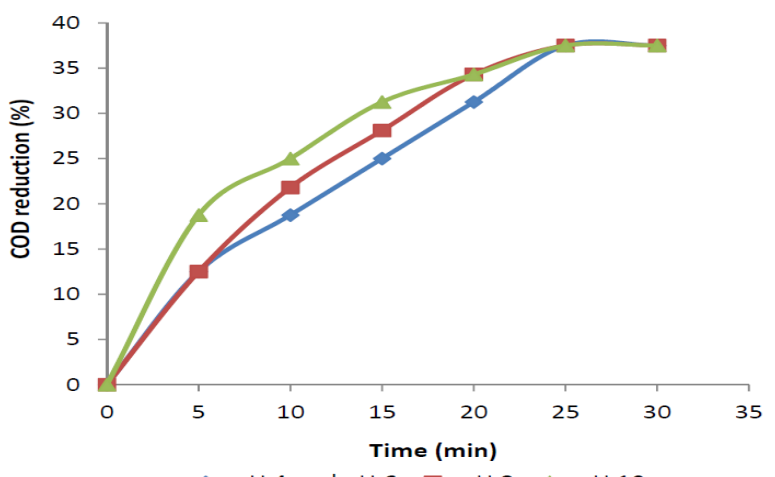

Figure 5. COD reduction of FSBAR treated effluent at various ozone doses.

Carboxylic acids have been indicated as products of melanoidin ozonation[15]. The reactivity of carboxylic acids with ozone has reported to be negligible[17]. It was observed by Arai et al.(1986) that the ozonation of humic substances also led to the formation of small molecules, mainly aldehydes(formaldehydes, acetaldehydes, glyoxal and methylglyooxal) and carboxylic acids(formic, acetic, oxalic, glyoxylic, pyruvic and ketomalonic acids) which accumulated in the solution due to their resistance towards further degradation by ozonation[18].

Pena et al.(2003) found that the ozonation of biologically pretreated molasses spentwash resulted in a COD reduction of $15 \%$ to $25 \%$ for the ozone dosage of $1.6 \mathrm{~g} / \mathrm{h}$ to $11.5 \mathrm{~g} / \mathrm{h}$ after 30 min reaction time[16].

\subsubsection{Variation in $\mathrm{pH}$}

The initial $\mathrm{pH}$ of the wastewater was 3.42. Ozonation was carried out without modifying the $\mathrm{pH}$ of the FSBAR treated effluent. Ozonation process led to a slight drop in the $\mathrm{pH}$ value of the wastewater to $3.1,3.08$ and 3.07 for the ozone dosage of $3.8 \mathrm{~g} / \mathrm{h}, 5 \mathrm{~g} / \mathrm{h}$ and $6.3 \mathrm{~g} / \mathrm{h}$ at the end of 30 min. This decrease in $\mathrm{pH}$ was due to formation of the acidic degradation products like caroboxylic acids due to ozonation of melanoidin compounds[15].

\subsubsection{Ozonation Efficiency}

This parameter represents the yield of ozone consumption and is defined as the ratio of ozone consumed and the ozone supplied in the reactor after a given time[10]. The efficiency values at different ozone dose after $30 \mathrm{~min}$ of reaction are summarized in Table 1. Maximum ozonation efficiency of $76 \%$ was observed at applied ozone dosage of $3.8 \mathrm{~g} / \mathrm{h}$. The ratios between colour(absorbance at $475 \mathrm{~nm}$ ) 
removed and grams of ozone fed into the reactor after 30 min of reaction are also summarized in Table 1. An increase in the applied ozone dosage yielded a reduction in the above defined ratio, thus, low ozone $\operatorname{dose}(3.8 \mathrm{~g} / \mathrm{h})$ was enough to oxidize coloured compounds efficiently. Greater ozone dosages did not enhance the ratio and ozone left the reactor without being consumed by decolourization reactions.

Table 1. Effect of Ozone Dosage on Ozone Efficiency and Colour Removal.

\begin{tabular}{|c|c|c|c|c|}
\hline $\begin{array}{c}\text { Ozone } \\
\text { dosage } \\
(\mathrm{g} / \mathrm{h})\end{array}$ & $\begin{array}{c}\text { Ozone } \\
\text { supplied } \\
(\mathrm{mg})\end{array}$ & $\begin{array}{c}\text { Ozone } \\
\text { consumed } \\
(\mathrm{mg})\end{array}$ & $\begin{array}{c}\text { Ozonation } \\
\text { efficiency } \\
(\%)\end{array}$ & $\begin{array}{c}\text { Colour removed } \\
\left(\mathrm{A}_{475}\right) / \mathrm{g} \text { ozone } \\
\text { supplied }\end{array}$ \\
\hline 3.8 & 1922.4 & 1463.5 & 76 & 0.49 \\
\hline 5 & 2383.2 & 1627.6 & 68 & 0.41 \\
\hline 6.3 & 3193.2 & 1710.3 & 54 & 0.31 \\
\hline
\end{tabular}

\section{Conclusions}

Ozonation was done on FSBAR effluent for decolourization. It was found that $\mathrm{pH}$ had a negligible effect on decolourization. Ozonation was performed at different ozone doses. $4.75 \mathrm{~g} / \mathrm{L}$ was found out to be optimum dose at applied ozone rate of $3.8 \mathrm{~g} / \mathrm{h}$ for $30 \mathrm{~min}$. The decolourization of $66 \%$ was obtained at this dose. The total decolourization obtained by the combined treatment(PAC treatment, FSBAR and Ozonation) was $96 \%$ and the total COD removal was $81 \%$. This shows that ozonation can be used effectively as tertiary treatment after fungal decolourization of digested distillery spentwash.

\section{REFERENCES}

[1] Pant, D. and Adholeya, A., 2007, Biological approaches for treatment of distillery wastewater: a review., Bioresource Technology, 98, 2321-2334

[2] Singh, S.S. and Dikshit, A.K., 2008, Biological Treatment of Distillery Wastewater: Various Options., Indian Journal of Environmental Protection, 28(3), 200-209

[3] Migo, V.P., Matsumara, M., Rosario, E.J.D.and Kataoka, H., 1993, Decolorization of molasses wastewater using an inorganic flocculant., Journal of Fermentation and Bioengineering, 75(6), 438-442

[4] Mohana, S., Acharya, B.K., and Madamwar, D., 2009, Distillery spent wash: Treatment technologies and potential applications, Journal of Hazardous Materials, 163, 12-25

[5] Chaudhari, P.K., Mishra, I.M. and Chand, S., 2007, Deco- lourization and removal of chemical oxygen demand(COD) with energy recovery: Treatment of biodigester effluent of a molasses based alcohol distillery using inorganic coagulants", Colloids and Surfaces A: Physicochemical and Engineering Aspects, 296, 238-247

[6] Singh, S.S., and Dikshit, A.K., 2010, Optimization of the parameters for decolourization by Aspergillus niger of anaerobically digested distillery spentwash pretreated with polyaluminium chloride., Journal of Hazardous Materials, 176, 864-869

[7] Singh, S.S., and Dikshit, A.K., 2011, Decolourization of anaerobically digested and polyaluminium chloride treated distillery spentwash in a fungal stirred tank aerobic reactor., Biodegradation, 22, 1109-1117

[8] Alfafara, C.G., Migo, V.P., Amrante, J.A., Dallo, R.F., and Matsumara, M., 2000, Ozone treatment of distillery slop waste., Water Science and Technology, 42(3), 193-198

[9] Pena, M., Coca, M., Gonzalez, G., Rioja, R. and Garcia, M.T., 2003, Chemical oxidation of wastewater from molasses fermentation with ozone., Chemosphere, 51, 893-900

[10] Beltran, F.J., Encinar, J.M. and Gonzalez, J.F. 1997, Industrial wastewater advanced oxidation. Part 2. Ozone combination with hydrogen peroxide or UV radiation., Water Research, 31(10), 2415-2428

[11] Sangave, P.C., Gogate P.R. and Pandit, A.B., 2007, Ultrasound and ozone assisted biological degradation of thermally pretreated and anaerobically pretreated distillery wastewater", Chemosphere, 68(1), 42-50

[12] APHA, 1998, Standard Methods for the Examination of Water and Wastewater. 20th ed. American Public Health Association, New York

[13] Langlais B., Reckhow, D. A. and Brink, D. R., 1991, Ozone in Water Treatment, Applications and Engineering. Chelsea, MI, Lewis Publishers, Inc

[14] Coca, M., Pena, M. and Gonzalez, G., 2005, Variables affecting efficiency of molasses fermentation wastewater ozonation., Chemosphere, 60, 1408-1415

[15] Kim, S.B., Hayase, F. and Kato, H., 1985, Decolorization and degradation products of melanoidins on ozonolysis., Agricultural and Biological Chemistry, 49(3), 785-792

[16] Pena, M., Coca, M., Gonzalez, G., Rioja, R. and Garcia, M.T., 2003, Chemical oxidation of wastewater from molasses fermentation with ozone., Chemosphere, 51, 893-900

[17] Hoigne, J. and Bader, H., 1983, Rate constants of reactions of ozone with organic and inorganic compounds in water. I. Non-dissociating organic compounds., Water Research, 17, 173-183

[18] Arai, H., Arai, M. and Sakumoto, A., 1986, Exhaustive degradation of humic acid in water by simultaneous application of radiation and ozone., Water Research, 36, 4243-4254 